Review

\title{
Applications of Chitin in Medical, Environmental, and Agricultural Industries
}

\author{
Uday Dave ${ }^{1,2}$, Esther Somanader ${ }^{1,2}$, Parnian Baharlouei ${ }^{1,3}$, Linh Pham ${ }^{1,2}$ and M. Azizur Rahman 1,2,*(D) \\ 1 Centre for Climate Change Research, Toronto, ON M3C 1R9, Canada; uday@climatechangeresearch.ca (U.D.); \\ esther@climatechangeresearch.ca (E.S.); parnian.baharlouei@mail.utoronto.ca (P.B.); \\ quelinh.pham@mail.utoronto.ca (L.P.) \\ 2 A.R. Environmental Solutions, ICUBE-University of Toronto, Mississauga, ON L5L 1C6, Canada \\ 3 Department of Physiology and Human Biology, University of Toronto, Toronto, ON M5S 1A8, Canada \\ * Correspondence: aziz@climatechangeresearch.ca or mazizur.rahman@utoronto.ca
}

check for updates

Citation: Dave, U.; Somanader, E.; Baharlouei, P.; Pham, L.; Rahman, M.A. Applications of Chitin in Medical, Environmental, and Agricultural Industries. J. Mar. Sci. Eng. 2021, 9, 1173. https://doi.org/ $10.3390 /$ jmse9111173

Academic Editor: Chiara Lauritano

Received: 7 September 2021

Accepted: 19 October 2021

Published: 25 October 2021

Publisher's Note: MDPI stays neutral with regard to jurisdictional claims in published maps and institutional affiliations.

Copyright: (c) 2021 by the authors. Licensee MDPI, Basel, Switzerland. This article is an open access article distributed under the terms and conditions of the Creative Commons Attribution (CC BY) license (https:/ / creativecommons.org/licenses/by/ $4.0 /)$.

\begin{abstract}
Chitin is a universal biopolymer that is found in microbes, plants, fungi, the exoskeleton of insects, various species of algae, and bottom-feeding crustaceans. This (1-4)-linked N-acetyl-BD-glucosamine polysaccharide can be readily processed with simple chemical procedures without putting a species at risk. Chitin has garnered interest as an alternative substance that can be used in the medical, environmental, and agricultural sectors. Indeed, chitin's unique nature of biocompatibility, being environmentally safe, and having innate water-solubility allows the polymer to be used in a wide range of applications. In this review, we discuss the possible applications of chitin in the medical, environmental, and agricultural sectors through an extensive search of the latest literature. Moreover, the following review summarizes and explores the new and current studies surrounding the practical uses of chitin to solve issues that are commonly induced by various chemicals which are invasive to the surrounding environment and species co-existing in that area.
\end{abstract}

Keywords: marine chitin; biopolymer; chitosan; agriculture; environment; polysaccharide

\section{Introduction}

Chitin is commonly found in the shells of crustaceans, the exoskeleton of various insects, cell walls of coralline algae and many other marine organisms, fungi, plants, and bacteria [1-3]. Chitin from marine sources has plenty of advantages over land animal sources, such as minor regulatory and quality control problems, an almost negligible presence of biological contaminants and toxins, low inflammatory response, and they are more metabolically compatible. This biopolymer has many applications within the medical (includes tissue regeneration, wound dressing, cancer treatment), environmental, and agricultural sectors (see Figure 1). Figure 2 shows that chitin is a major (1-4)-linked $\mathrm{N}$-acetyl- $\beta$-D-glucosamine polysaccharide that gives species a hard exterior [2-5]. The unique characteristics of chitin mirror the similar structure found in cellulose, but in chitin, an acetamide group is found on the $\mathrm{C}-2$ position rather than a hydroxyl group at the same position (see Figure 2). Chitin itself has three different structures denoted as $\alpha, 1$, and $\gamma$ (Figure 3) that differ in the orientation of chains that are either bonded in piles or sheets connected by hydrogen bonds through various amide groups $[2,3]$.

The major differences between $\alpha$ and $B$ are the piles of chains that are connected antiparallel in $\alpha$-chitin versus parallel in $B$-chitin (Figure 3). Through X-ray diffraction (XRD), $\alpha$-chitin has been identified as having stronger intersheet and intra-sheet hydrogen bonding, whereas $B$-chitin has weaker intra-sheet and intersheet bonding [2,3]. However, $B$-chitin found in squid has been known to have higher solubility, higher reactivity, and higher affinity for solvents than $\alpha$-chitin [2,3]. Lastly, XRD analysis has shown that $\gamma$-chitin has both antiparallel and parallel chains (Figure 3 ) but a more similar overall pattern to $\alpha$ than 8 -chitin [2,3]. 


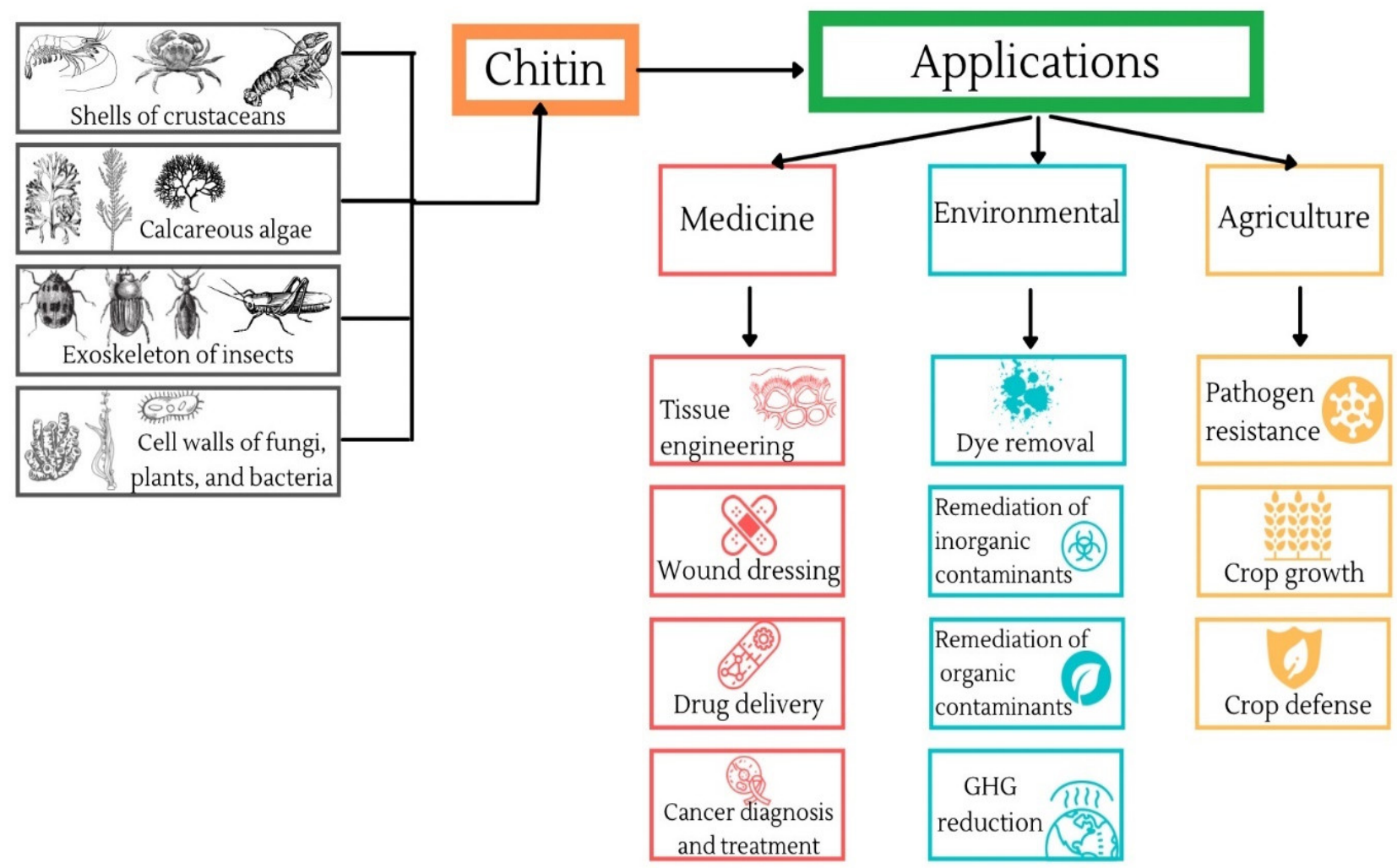

Figure 1. Sources of chitin and its applications at a glance.
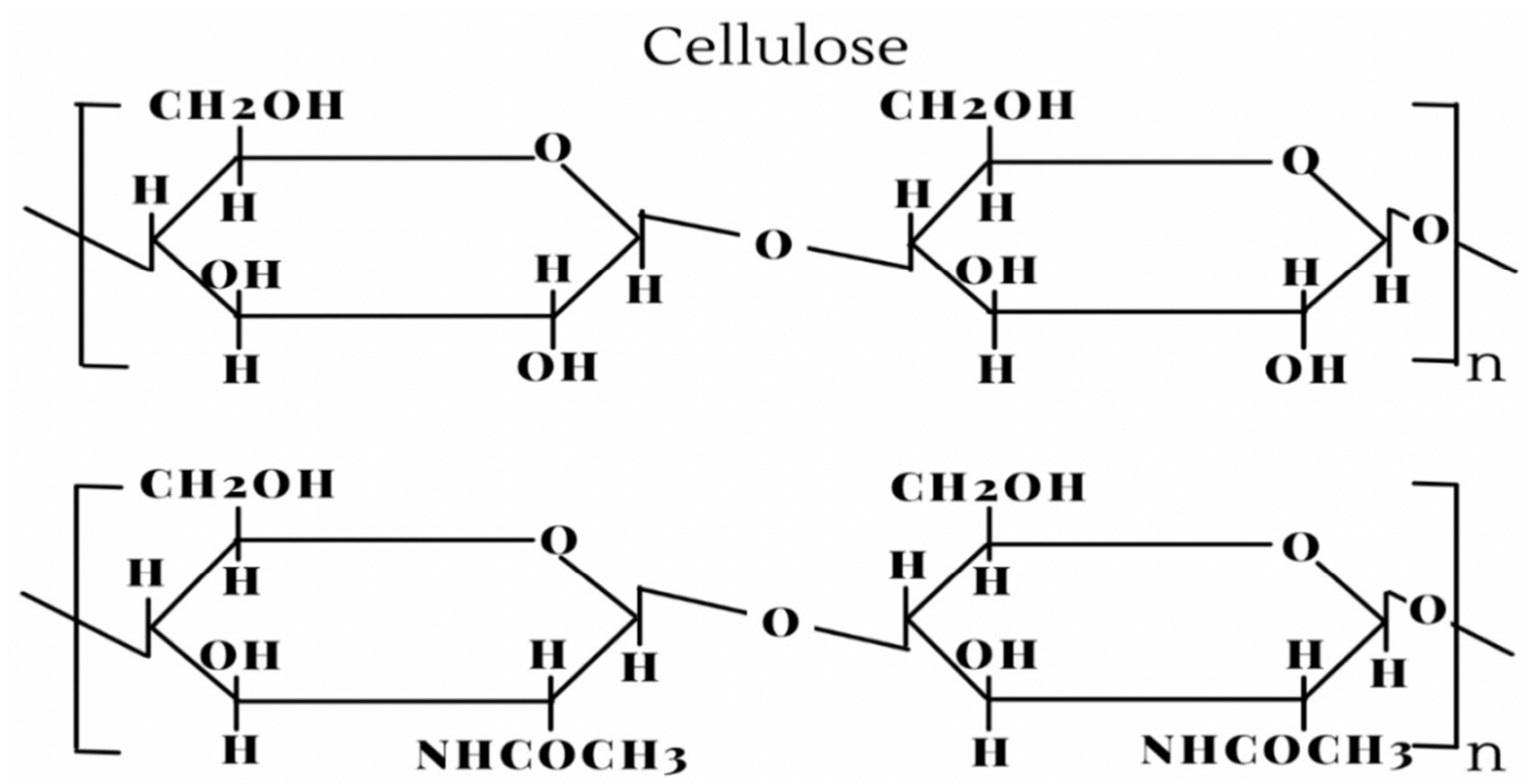

Chitin

Figure 2. Molecular representations of chitin and cellulose. 


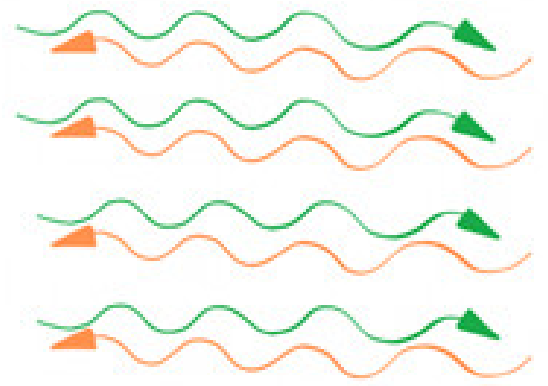

a-chitin

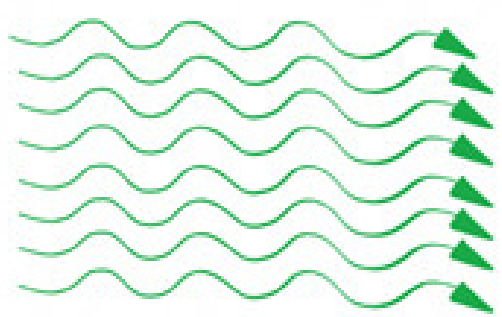

$\beta$-chitin

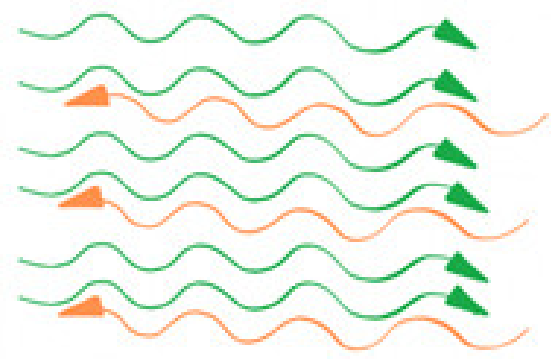

Y-chitin

Figure 3. Visualization of antiparallel piles of chains found in $\alpha$ and $\gamma$ chitin versus parallel ones found in B-chitin.

The functional role of chitin varies from species to species as a form of protection, structural support, or both. In the exoskeletons of crustaceans, the biomineralization structure is comprised of an organic matrix using $\alpha$-chitin combined with an inorganic mineral, like calcium carbonate [6]. The combination of these two elements gives a specific microstructure that provides mechanical strength for protection and flexibility for movement [6]. Coralline algae, a type of marine calcifier which uses a similar organic matrix that controls the formation of calcium carbonate for biomineralization, has demonstrated in past studies that chitin contributes heavily to this process [5]. Previous studies have found that the chitin-rich organic matrix affects the formation of Mg-calcite that gives the skeleton a hard, rock-like appearance [5]. In insects, an exoskeleton is developed through a cuticle in which the main structural component is chitin $[7,8]$. Chitin itself is found on many internal structures in both insects and arthropods, like the alimentary canal $[7,8]$. This canal, found in most insects, has a complex known as the chitinous peritrophic matrix (PM), which is important for the insect's intestinal tract and protects epithelial cells from mechanical damage $[7,8]$. With all of the information above, scientists are now looking at different techniques to extract chitin from various species for practical applications. This review will highlight and discuss different applications of chitin to be used as an alternative or a solution to problems that are affecting the medical, environmental, and agricultural industries.

\section{Production of Chitin}

Chitin formation is controlled by an enzyme known as chitin synthase that actively binds monomers of $\mathrm{N}$-acetyl-glucosamine to form chitin polymers [9]. A schematic representation of $\mathrm{N}$-acetyl-glucosamine formation into the chitin polymers has been shown in Figure 4. In the epithelial cell membrane of chitin-producing species, on the apical side, exists chitin synthase that synthesizes the biopolymer directly into the extracellular space $[9,10]$. Figure 4 shows that chitin production includes several cascading events which start by using sugars, like trehalose or glucose that are transformed through phosphorylation and amination to form UDP-N-acetylglucoamine [11,12]. Next, chitin synthase genes, commonly found in fungi and crustacean DNA, are transcribed to produce chitin synthase which is then translocated to the cytoplasmic membrane and activated [11,12]. Exposing the catalytic domain intracellularly allows for UDP-N-acetyl glucosamine to be hydrolyzed by the membrane-bound glycosyltransferase, releasing uridine diphosphate (UDP) to form a growing N-acetyl-13-D-glucosamine polymer [11,12]. However, post-catalytic events such as the transfer of chitin polymers across the plasma membrane are not as well understood [11,12]. Once across the plasma membrane, through fibrillogenesis, chitin chains bind together to form microfibrils that provide a basic foundation for a cuticular macromolecular structure [11,12]. Transporters like those of the ABC (ATP-binding cassette) family play a significant role in actively transporting substrates across the lipid membrane [13]. The ABC transporter sulfonylurea (SUR) can assist in chitin synthesis, and when inhibited, 
can somewhat affect the rate at which chitin can form an extensive exoskeleton in various species [13]. When sulfonylurea receptors are not inhibited, they help in the formation of an organic matrix that is commonly found in arthropods and Rhodophyta which contain species like coralline algae that are helically stacked $[1,14]$. Organic matrices are used as a template for nucleation and the controlled deposit of minerals, such as calcium carbonate in conjunction with the enzymatic oxidation of phenols or catechols, which give species their hardened rigid exterior $[5,14]$. Various proteins play a key role in the composition of calcium storage organs found in these species, specifically in crustaceans which have a gastrolith [15]. The gastrolith is made up of four proteins: GAP 65, GAP 10, gastrolith matrix protein (GAMP), and orchestin, which is a phosphoprotein [15].

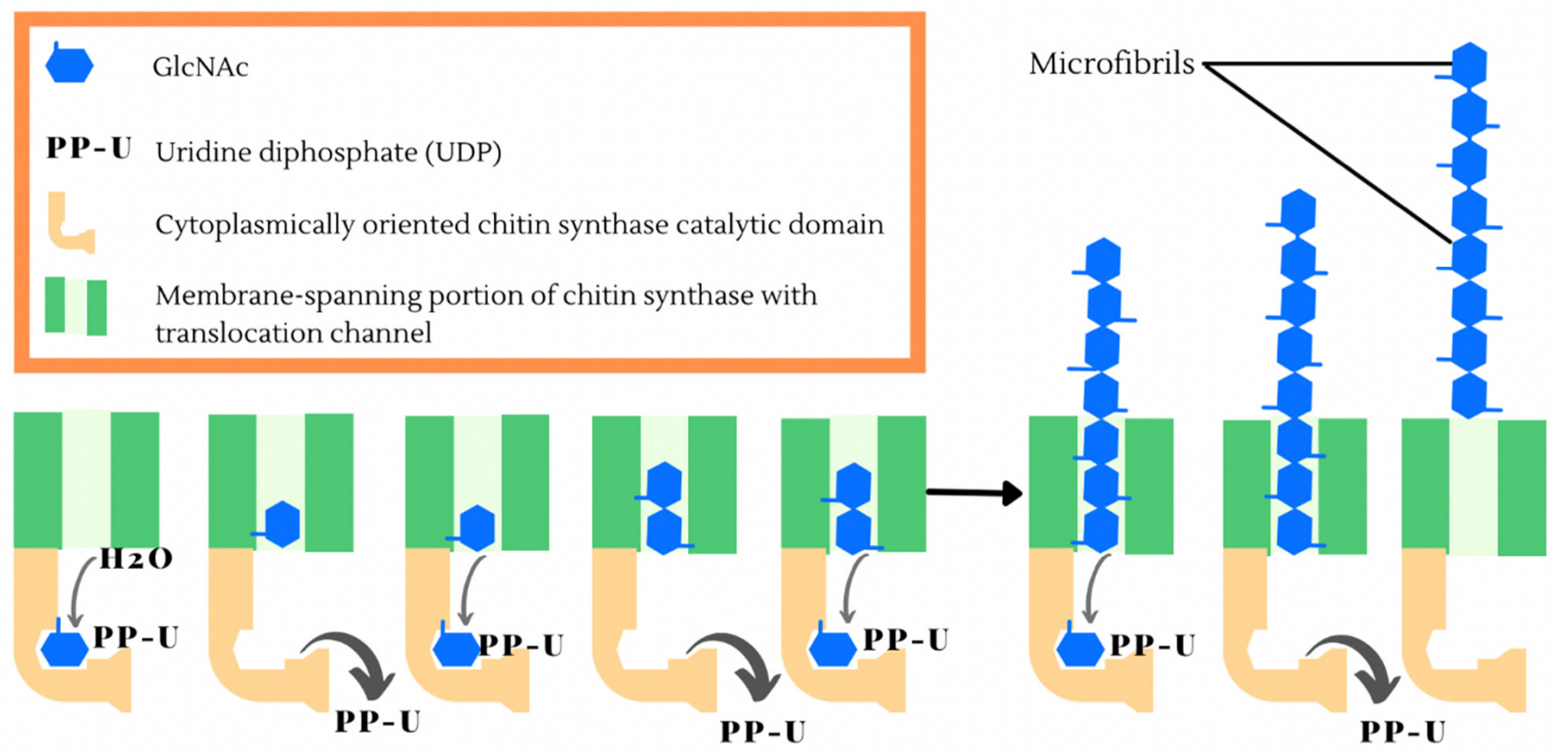

Figure 4. Schematic representation of N-acetyl-glucosamine formation into the chitin polymers.

Before addressing the different applications of chitin, it is important to understand how chitin is extracted using relevant techniques from species where the biopolymer exists. Crustacean species produce major waste from seafood processing plants [16]. Yearly reports have shown that an average of 6-8 million tons of crustacean waste is produced $[17,18]$. Crustacean shells are removed as waste biomass that contains up to $15-40 \%$ of chitin $[17,18]$. To ensure there are no harmful by-products produced from waste biomass, scientists have developed new ways to utilize this waste product by extracting chitin from the shells of crustaceans $[16,18]$. The most reliable method to isolate chitin involves mechanical and chemical processes which include grinding the shells of crustaceans into a fine powder followed by applying a demineralization agent with a strong acid, like hydrogen chloride [17-19]. Once all calcium salts are removed, the next stage is deproteination with an alkali medium, such as Sodium Hydroxide stirred vigorously at $90-100{ }^{\circ} \mathrm{C}$ to remove all traces of protein [17-19].

The final step involves a discoloration and bleaching mixture of chloroform, methanol, and water to remove any lingering pigment $[16,20]$. Once these steps are completed in sequential order, only then can you achieve raw chitin [16,20]. However, an area of concern would be the production of large quantities of contaminants, such as high concentrations of mineral acids used for the isolation process that are very hazardous $[16,19,20]$. As an alternative, scientists are now introducing microbial fermentation and proteolytic enzymes as a more biologically friendly way to demineralize and deproteinize crustacean shells to remove raw chitin $[16,19,20]$. While the grinding and discolouration steps largely remain the same, for demineralization, instead of using harmful acids, researchers use acid- 
producing bacteria, like Bacillus licheniformis and Bacillus subtilis $[16,19,20]$. These strains of bacteria are fermented at optimal conditions $\left(30-40^{\circ} \mathrm{C}\right)$ and take roughly $3-5$ times longer to complete the process $[16,19,20]$.

The next best source for chitin can be found in insects, and this has accumulated more interest due to the ever-increasing biodiversity [21,22]. Considering the nature of insect cuticles, which have much lower concentrations of inorganic materials, the steps for demineralization are not as environmentally impactful as crustacean shells [21,22]. Previous studies looked at the characterization of chitin in the Chinese crop pest Holotrichia parallela and silkworm pupa Bombyx mori [21,22]. These studies found that chitin in the cuticle, which has a significant role in insect exoskeleton development, is covalently bound to catechol compounds and sclerotin proteins [19]. To isolate chitin from these compounds, a similar chemical procedure must be applied [21,22]. Like crustacean shells, ground up Holotrichia parallela and Bombyx mori were demineralized with $\mathrm{HCl}$ to remove the catechol bonds, which was followed by similar deproteinization with $\mathrm{NaOH}[21,22]$. Finally, decolorization was performed with potassium permanganate solution, leaving a light brown, raw chitin product that was then left to dry [21,22].

\section{Medical Applications of Chitin}

Chitin and chitosan, a derivative of chitin, have demonstrated various applicable uses in the medical sector due to their high biocompatibility [23-29]. This is mainly attributed to chitosan's ability to be biodegraded through enzymes, like lysozyme, which can separate the bond between acetylated units and break chitosan into oligosaccharides [23]. Alongside degradability, chitin also possesses immunogenicity and mechanical strength [23]. Chitosan also has the unique ability to become protonated, which means it can bind and form complexes with other molecules that are negatively charged, e.g., growth factors, nucleic acids, and cytokines [23]. Binding with these negatively charged molecules does not allow them to be broken down. Instead, there is an increase in the concentration of molecules that can be used for tissue regeneration [23]. In short, tissue engineering is a process that involves technical advancements in the medical field in combination with molecular and cellular biology to replace damaged or lost tissues and organs and contribute to wound healing and dressing [23-28,30]. Scientists are now looking at chitin and subsequent derivatives for tissue regeneration due to the many favorable biological properties that come with the biopolymer, such as the low cost of isolation and fast production, enabling easier industrial use [23-29].

\subsection{Tissue Engineering}

To understand tissue regeneration using active bio-materials, there must be an understanding of how chitin works with damaged tissues and how it enables regrowth. The foundation of tissue engineering is built upon the idea of a biomaterial scaffolding that gives a cell the desired shape and structure [24,25]. Biomaterial scaffolding goes through changes where, for example, chitin is combined with smaller molecules such as sugars and peptides [24,25]. Previous hybrid studies on binding fibers of chitin with silk-fibroins and polyglycolic acid have demonstrated the connection and spreading of human keratinocytes and fibroblast. Both keratinocytes and fibroblasts are important cell types that are responsible for the innate inflammatory response in cutaneous repair and regeneration processes [26,27].

Using the information above, researchers are now looking at whether or not chitin can be useful in supporting the regeneration of cartilage [24]. This would be attributed to the repeating subunits of N-acetyl-B-D-glucosamine that are the foundation of other glycosaminoglycans, like keratin sulfate and hyaluronate, which are key components of articular cartilage [24]. Cartilage is a very promising nominee for tissue engineering research programs due to chondrocytes being easily isolated through enzymatic digestion [28,29]. It has been well documented that cartilage grafts grow on biodegradable scaffolds, like polylactic and polyglycolic acids [28,29]. However, chitin has an advantage over these synthetic 
polymers as a result of the biopolymer's ability to bind with the glycosaminoglycans of cartilage $[28,29]$. Furthermore, previous studies have also shown that chondrocytes have a unique spherical morphology and exhibit type II collagen and aggrecan when developed on chitosan films [28,29].

Another promising avenue is the development of chitin-based tubes for tissue engineering found in the nervous system [23,30]. One study focused on using straightforward acylation chemistry in combination with molding techniques to produce chitin and chitosan gel tubes which can have positive mechanical properties, acting as nerve guides on in vitro dorsal root ganglion (DRG) neurons [23,30,31]. The study found that chitosan tubes were much stronger when measuring transverse compression than chitin tubes in terms of the various degrees of acetylation, enabling to support displacing loads [23,30,31]. In vitro analysis confirmed that both biopolymers showed adhesion and differentiation found in the DRG neurons, but chitosan caused better neurite outgrowth than chitin [23,30,31]. Simply changing the amine content can promote better adhesion and neurite extension, both of which are key for tissue engineering in the nervous system [23,30,31].

\subsection{Wound Dressing}

Wounding healing is another avenue where researchers are looking at potential applications of chitin to be used as an alternative to conventional methods. The healing process of a wound is continuous and complex, as there are five important stages: homeostasis, inflammation, migration, proliferation, and maturation [32,33]. One of the many problems plaguing the wound healing process would be a bacterial infection that, if not managed correctly, could lead to life-threatening complications [34]. When picking the ideal candidate for wound dressing material, many different factors go into finding the best options, like allowing for gaseous exchange, providing protection from microorganisms, and ensuring no harm is done to the patient [34]. The current market has many different products that not only maintain the microenvironment on the surface of the wound, as newer technologies have started using bioactive products that also control and initiate the healing process in a safe manner $[32,33]$.

Chitin and its derivatives can act as a wound healer accelerator by controlling the inflammatory response through interleukin 8, prostaglandin $\mathrm{E}$, and interleukin $1 \mathrm{~B}$. This characteristic, alongside chitin's ability to be utilized in different sectors, allows chitin to be a promising source for wound dressing. [35,36]. As mentioned before, the use of chitin and chitosan scaffolds in patients with severe burns and wounds has shown promising results $[35,36]$. In conjunction with chitin having excellent antibacterial properties, metallic silver and silver sulphadiazine ointments have also been illustrated to have good antibacterial resistance $[29,30]$. Alone, each material can have a profound effect on wound treatment, but researchers are now looking at the possibility of combining the two $[35,36]$. A previous study found that the combination of $\alpha$-chitin and nano-silver into scaffold composites has above-average antibacterial activity and great blood clotting ability against different microbes, such as Staphylococcus aureus and Escherichia coli [35,36]. A similar composite scaffolding was also made by using $\AA$-chitin and nano-silver, demonstrating anti-bactericidal efficacy on microbes, whole blood clotting, and the composites showed good cell attachment $[35,36]$. The slight difference between both types of chitin can be attributed to differences in the intermolecular interactions $[35,36]$. The intermolecular interactions in $\beta$-chitin are drastically weaker than those commonly found in $\alpha$-chitin, causing $ß$-chitin to allow for better dissolution in many different solvents and making them more reactive and adaptable [35,36].

The above information has allowed researchers to test the idea of wound healing using biopolymers like chitin on live animal subjects under controlled conditions. A study using a rat model saw animals being anesthetized and shaved to reveal the skin surface [24]. After this was performed, a circular wound was surgically created on the left and right dorsal sides of the rodent [24]. Chitin films were created by taking raw powered chitin and dissolving it in $5 \% \mathrm{LiCl} / \mathrm{N}, \mathrm{N}$-dimethylacetamide, producing a $0.5 \%$ solution [24]. 
This solution was later poured into molds which created chitin gels, producing the films that were placed on the wounds [24]. After four days of healing, the traditional gauze dressing had noticeable hardening which caused tissue damage to occur, affecting the healing process that was not noted in chitin films [24]. After seven days, the regeneration of the wound's epidermal surface was $70 \%$ healed, but there was a stark difference between wounds that were dressed with chitin films, as they healed much faster than traditional dressing [24]. After 14 days, the inflammatory phase and regeneration of the epidermal surface had not fully healed in both dressings, but it was recorded that chitin films had a stronger inflammatory response [24]. Overall, the use of chitin films can allow wounds to heal dramatically faster and stronger than conventional wound dressing materials [24].

The previous examples demonstrate chitin's ability to act as a promising source for wound dressings. Furthermore, studies have shown that chitin's derivative, chitosan, also demonstrates this same ability, specifically when combined with other materials or even with its own derivatives. Hu et al. [37] created a composite sponge for the purpose of wound dressing. In this study, chitosan-based sponges are considered an effective hemostatic dressing due to their interconnected porous structures, good swelling capacity, antibacterial activity, and hemostatic ability. However, the sponges themselves cannot preserve the moistness of the wound and could cause secondary damage when used as a wound dressing due to their poor hydrophilicity [37]. Hydroxybutyl chitosan is created when hydroxybutyl groups are conjugated to the C-6 hydroxyl and C-2 amino groups of chitosan. These modifications provide chitosan with water solubility, temperature-sensitive properties, and ensure that the transition from an aqueous to hydrogel phase is reversible. Furthermore, the hydroxybutyl sponge still retains properties such as high porosity, good hydrophilicity, non-toxicity, and tissue adhesion [37]. While all of these characteristics provide a solid basis for wound healing, due to the hydroxybutyl modification, this sponge lacks effective antibacterial properties and mechanical strength in hydrated states [37]. Therefore, the authors decided to combine chitosan and hydroxybutyl chitosan, at different ratios, to determine whether their individual characteristics could cover each other's failings [37]. The authors performed different tests, including an in vivo wound healing test on male Sprague-Dawley rats to evaluate the skin tissue reconstruction. It was determined that the composite sponge had better water retention, erythrocyte aggregation, and antibacterial activity when compared to the pure chitosan sponge and the hydroxybutyl sponge. Furthermore, the composite sponge was also able to induce higher cell proliferation and could support epithelial cell growth. Overall, the authors proved that the composite sponge had great potential to act as a wound dressing [37].

Ehterami et al. [38] attempted to create a hydrogel that was comprised of alginate, chitosan, and vitamin E due to their high performance in skin tissue engineering. The complexation between alginate, an anionic polymer typically derived from brown seaweed, and chitosan is an effective method to create microspheres and improve chitosan's properties regarding medical applications [38,39]. Furthermore, vitamin E, typically recognized for its role as an antioxidant, can also regulate gene expression, transcription, and the expression of connective tissue growth factor [38]. These properties enable the protection of wounds from infections. The authors found, based on their testing of thirty-six male Wistar rats that had been administered wounds, that the prepared hydrogel dressings had a higher wound closure than the wounds treated with gauze (the control) [38]. Furthermore, one of the hydrogels, the Chit/Alg/400 IU Vit E, demonstrated the most promise regarding cell proliferation rate and accelerated wound healing [38]. The authors were able to demonstrate, through this study, the effectiveness of their prepared hydrogels in wound healing, with chitosan being one of the primary components [38].

While these are only a few examples of chitin and chitosan in the wound healing process, it is clear that both these polymers have immense potential, especially when combined with other materials. 


\subsection{Drug Delivery}

With all the advancements in the biomedical field using chitin, new developments have allowed the biopolymer to be used for drug delivery. Biopolymers, as mentioned before, have multiple applications due to their multifunctionality, applied as beads, microparticles, nanoparticles, micelles, hydrogels, tablets, and capsules [40,41]. Biopolymers, such as chitin have the ability to be formed into nanogels, which are hydrogels restricted to the nanoscopic field [40,41]. These nanogels have intensive properties, including size tunability, a large surface area for bioconjugation, drug loading abilities, controlled release, and an excellent ability to respond to environmental stimuli $[40,41]$. Through these properties, novel uses for chitin in drug delivery have been developed, such as water-soluble carboxymethyl chitin (CMC) and polylactic acid(PLA)/chitosan(CS) nanoparticles.

CMC nanoparticles can be used as an innovative way to deliver drugs to different cell types and areas within the cell [26]. Studies have shown that CMC can lower the adsorption of blood components without causing an antibody response that could be induced by the body [26]. The raw chitin, before the initial reaction, is pretreated with a solution of $60 \%$ sodium hydroxide at $-20^{\circ} \mathrm{C}$ for roughly $12 \mathrm{~h}[42,43]$. Once this is completed, the main preparation of CMC is prepared by mixing raw chitin powder and monochloroacetic acid in an isopropyl alcohol solution that produces a condensation reaction [42,43]. The water solubility that makes CMC unique is determined by the concentration of sodium hydroxide that is available during the preparation of alkali chitin in certain freezing processes $[42,43]$. CMC and drug delivery operate on a two-step hydrolysis process that allows for controlled drug delivery $[42,43]$. The drug is bound to a peptide spacer which is then bound to CMC and is hydrolyzed by lysozymes, allowing the drug to be released [42,43]. Another study that combined CMC gels and doxorubicin, an anticancer drug, found the release of the drug from the gels was sustained over a period, which resulted in researchers wondering whether CMC can be applied to other drugs and vaccines [42,43].

Another novel technique that has garnered interest among researchers as an alternative method for drug delivery is the use of polylactic acid (PLA)/chitosan (CS) nanoparticles. PLA is another biodegradable polymeric material that is known to have low toxicity, good biocompatibility, and bio-absorbability in many in vivo studies [44,45]. Due to the low hydrophilicity and increased crystallinity of the biopolymer, the rate of degradation is lower due to bad soft tissue compatibility [44,45]. A previous study sought to find out if PLA/CS nanoparticles were an adequately controlled system to deliver the drug lamivudine, an antiretroviral drug used in the prevention and treatment of HIV / AIDS [44,45]. The study found that the combination of the two nanoparticles saw a decrease in the release rate of the drug as the $\mathrm{pH}$ of the solution shifted from alkaline to acidic, which was hypothesized to be the cause of repulsion of $\mathrm{H}^{+}$ions and other cationic groups, but overall it was concluded that PLA/CS nanoparticles represent a valuable alternative for the delivery of anti-HIV drugs $[44,45]$.

\subsection{Cancer Diagnosis and Treatment}

The diagnosis, treatment, and prevention of cancer using the emerging field of nanotechnology has changed significantly over time [46]. The use of nanoparticles, which are both biocompatible and capable of labeling certain molecules, has received much attention in the discussion of cancer diagnosis [46]. Semiconductor nanocrystals (or quantum dots (QD)) are engineered nanoparticles that can be used as fluorophores for in vivo imaging, including the bioimaging of cancerous tissues [46,47]. Although QD is a novel method for biomedical applications, its use faces challenges, including its toxicity due to the heavy metals (e.g., cadmium) that are released into the body. Other factors related to QD, including size, surface charge, concentration, and photodegradation also contribute to their cytotoxicity [46].

For these reasons, there is a need to develop other methods for diagnosing cancer. The expression of mannose receptors has been found to increase on cancer cells, and as a result, these receptors can serve as targets for nanoparticles [35]. Zinc sulfide (ZnS) nanoparticles 
surrounded by chitosan and functionalized with D-mannose can emit strong fluorescent radiation when targeting mannose bearing KB tumor cells [35]. These nanoparticles do not attach to the normal cells because normal cells do not increase mannose receptor expression [35].

In addition to the efficacy of mannosylated $\mathrm{ZnS}$ nanoparticles encapsulated by chitosan as in vivo fluorescent imaging for cancer diagnosis, chitosan derivatives may also have antitumor effects. Colonization of lung cancer is prevented by 6-O-sulfated chitin, and interestingly, the degree of sulfation is proportional to the inhibition of colonization [47]. In addition, the antitumor effects against sarcoma 180 solid tumors in BALB/C mice and MM-46 solid tumor implanted in $\mathrm{C} 3 \mathrm{H} / \mathrm{HC}$ mice are recognized by hexameric and heptameric $\mathrm{N}$-acetyl chitosan oligomers, which have been shown to increase the cytotoxic proliferation of T-lymphocytes due to the increased production of lymphokines by hosts, such as Interleukin 1 and Interleukin 2 [47].

\section{Environmental Applications of Chitin}

Chitin's environmentally friendly nature has been well documented, further allowing scientists to develop novel techniques utilizing chitin in the environmental sector. Chitin has a very high surface area due to the size of the biopolymer, which is applicable as a pollutant absorber and is used for other modifications that can be made into nanocomposites, best suited for environmental applications for soil and water pollutants [48,49]. Properties like microbiological degradation resistance, the innate ability to bond with different amino and hydroxyl groups, and its attraction to heavy metals allow chitin to utilize various elements that can sense and target different environmental hazards [48,49]. Recently, it was reported that chitin also has a vital role in the marine environment by protecting an abundant group of coralline algae from the negative impact of ocean acidification [1,5]. Further, this section will follow the common uses of chitin and the different derivatives associated with the biopolymer and will show distinct avenues in which such versatility can be used as an alternative solution to many common environmental problems.

\subsection{Dye Removal}

Water pollution is a major environmental concern that intersects with human health $[50,51]$. More specifically, surface and groundwater are at the most risk from pollution due to organic dyes which can catastrophically affect living organisms, causing illness, diseases, and in rare cases death [50,51]. Many colouring agents in pharmaceuticals, pesticides, and rubbers are known to contain a dye called Methylene blue [50,51]. When consumed at very low doses, Methylene blue is known to cause hemolytic anemia and skin peeling found in infants [50-52]. While chemical modifications, such as catalyst oxidation, membrane separation, coagulation/flocculation, and adsorption, have all been used to remedy these effects, there are several disadvantages and risks associated with these modifications $[50,51]$. In terms of disadvantages, most of the techniques listed above either produce secondary pollutants or have a high cost for producing the raw material to effectively remove the dye $[50,51]$. With such circumstances, researchers have now looked at organic possibilities that could remedy water pollution with compounds like chitin.

While there have been studies demonstrating the benefits of chitin, further research surrounding chitin as an alternative solution to issues regarding water systems must still be done. Previous studies have shown that the element itself must be modified to be used in certain situations to unlock the true potential of the biopolymer [53,54]. A recent study found that altering the structure of chitin into chitin nano-whiskers can be a promising solution for water treatment due to the functional groups associated with the nanomaterial and the high surface-to-volume ratio $[53,54]$. Several studies have been conducted with the purpose of wanting to understand the adsorption abilities of chitin nano-whiskers for organic dyes like crystal violet and carmine in different aqueous solutions $[53,54]$. First, chitin nano-whiskers were prepared using raw chitin that was hydrolyzed using hydrochloric acid, which was then subsequently boiled, cooled, and placed in centrifuged to 
obtain the desired structure [53,54]. The result showed that as the experimenters increased the concentration of chitin and chitin nano-whiskers from $29 \%$ to $66 \%$ and $41 \%$ to $90 \%$, there was an increase in the amount of crystal violet removed from the solution [53]. The same was recorded in the removal of carmine dye, which saw an adsorption efficiency of roughly $85 \%$ [54]. Furthermore, it was determined that raising the $\mathrm{pH}$ level from basic to more neutral conditions and the unique interaction of hydrogen bonding from the nanowhisker structure saw a further increase in the amount of crystal violet and carmine dye removed from the solutions $[53,54]$.

Chitin's ability to adsorb dyes has been well documented due to the biopolymer's innate structure, but the next step is determining whether or not combining the biopolymer with another compound can strengthen the rate at which dyes are removed from a solution. Another recent study wanted to determine the relationship chitin has with carbon allotropes $[55,56]$. It has long been established that carbon, specifically charcoal, can be used for water purification mainly due to its high degree of porosity and its unique surface structure $[55,56]$. Moreover, carbon allotropes like graphene have drawn interest from the scientific community as a new nanostructure material that can be applied to solve water pollution $[55,56]$. However, the structure of graphene must be modified due to its poor solubility and lack of polar groups that could limit adsorptions $[55,56]$. Therefore, a novel method has arisen that would increase the hydrophilicity and reactivity through oxidative exfoliation to form graphene oxide [55,56]. Thus, when forming a composite of chitin and graphene oxide, it would theoretically increase and improve the rate of absorption that is limited when using either compound alone [55,56]. Studies wanting to understand this relationship have sought to test this hybrid on three common dyes, namely remazol black, neutral red, and methylene blue $[55,56]$. After experimentation, it was found that the control, chitin, and the hybrid were able to adsorb the dyes, but treatments were determined to be $\mathrm{pH}$ - and proportion-dependent [55]. The study concluded that chitin and graphene oxide hybrids are a promising direction with amazing functional properties, such as dimensional stability, universally adsorbent for cationic pollutants, high adsorption capacity, and ease of regeneration $[55,56]$. When considering the practicality of other chemical alternatives, key limiting factors, such as the $\mathrm{pH}$ of the dye and ratio of the hybrid compounds, must be considered as well for the successful treatment of water pollutants [55].

\subsection{Remediation of Inorganic Contaminants}

Many environmental agencies have now determined a new substantial ecological and global health risk that plagues our water filtrations systems in the form of heavy metals [57]. The determining factors that classify elements as heavy metals are the following: naturally occurring elements that are unique for their high atomic weight/density and at low concentrations are hazardous or toxic if consumed $[57,58]$. These metals must be removed from aquatic environments as they are refractory, cannot break down, and attach to and accumulate in organisms $[57,58]$. Heavy metals such as chromium are commonly found in leather tanning, pigment production, and stainless-steel manufacturing [57]. Heavy metals found in water systems can result in toxic effects that can be additive/synergistic or antagonistic to all those that drink and use the contaminated water $[57,58]$. The ecofriendly nature of chitin being another alternative source of coagulants and flocculants can be used to remove metal ions from contaminated water systems $[57,58]$. The ability of chitin, specifically chitosan, to catatonically change the medium to support ion-exchange interaction and electrostatic attraction can be manipulated to allow for the dissolution and absorption of the heavy metal from a solution $[57,58]$.

With our comprehensive understanding of how chitin works with heavy metals, research has now shifted to using a composite material that compliments the structure of chitin to further improve the adsorption of inorganic contaminants. As it has been long established that metals are non-biodegradable, the removal of potentially harmful metals from waste requires different techniques, such as precipitation, ion exchange, cementation, 
electrodepositing, and membrane separation $[59,60]$. These techniques are legally mandated and follow heavy scrutiny for proper waste management. However, the high cost may result in researchers finding other novel techniques that are more cost-effective $[59,60]$. As mentioned before, chitin itself is limited in its adsorbent capabilities due to its relatively low mechanical and chemical resistance to other biopolymers, affecting real scale adsorbent rates $[59,60]$. Due to this common flaw found in the molecular structure of chitin, it was determined that forming a bio-composite with chitin and other synthetic compounds would drastically increase adsorption capabilities $[59,60]$. The reasoning behind this idea came from studies proving that different combinations of the composite material would have increased strength even at high temperatures with higher corrosion and oxidation resistance $[59,60]$. Of those different combinations with chitin, bentonite has much better resistance to an acidic environment and adsorption capacity [59,60]. A previous study wanted to understand the effect of chitin-bentonite bio-composite adsorption abilities concerning chromium found in an aqueous solution $[59,60]$. The results showed that the bio-composite was heavily $\mathrm{pH}$-dependent, testing within a $\mathrm{pH}$ range of 2-9, and that the maximum percent of chromium removed from the solution was at a $\mathrm{pH}$ of 4 . However, the removal of chromium declined as the $\mathrm{pH}$ became more basic $[59,60]$. Overall, the study concluded that the chitin-bentonite bio-composite has high potential as an alternative to traditional adsorption methods, but $\mathrm{pH}$ is a factor that must be considered $[59,60]$.

\subsection{Remediation of Organic Contaminants}

Another growing concern regarding water filtration systems is the removal of organic contaminants. Organic contaminants represent another subsection of water pollutants that are not only harmful to humans, but also to neighboring ecosystems, where the compounds leach out [61]. The substances that fall under the classification of organic contaminants include pesticides, pharmaceuticals drugs, illicit drugs, endocrine disrupting compounds, steroids, hormones, fire/flame retardants, volatile organic compounds, and aromatic hydrocarbons [61,62]. Pesticides are used on crops by farmers to remove weeds and unwanted pests but can be highly toxic when exposed indirectly or directly to the human body as they can bioaccumulate through the food chain $[61,62]$. Pharmaceutical drugs, a staple of modern medicine, are key to warding off infections and diseases, but if improperly handled and disposed of, may become disease carriers and can have various adverse effects on aquatic systems [61,62]. The toxic by-products of many synthetic chemicals in liquid form can transition into a state of various volatile gases and when exposed to the environment can have harmful effects to those exposed [61].

With all the negative effects associated with organic contaminants leeching into our water systems, scientists are now looking for more environmentally friendly bio-sorbents that will remedy pollutants as much as or better than conventional practices. Pharmaceuticals are very different from normal water contaminants, as they are made to be biologically active at low concentrations well before reaching the targeted area [63]. By design, this allows for bioaccumulation with relative ease, causing harmful effects on aquatic ecosystems [63]. This is why researchers are using the adsorption methods recorded in many studies as another way to remove waste from water [63]. A recent study tracking the adsorption abilities of chitin and lignin tested hazardous non-steroidal anti-inflammatory drugs to determine if binding both biopolymers was a better choice than conventional methods [63]. The limitation of chitin at the molecular level has been well studied, but lignin can further strengthen the structure, making it more adaptable for functional groups and a much better adsorber for hydrophobic impurities [63]. The results showed that chitin/lignin bio-sorbents follow pseudo-second-order, which means the model was relatively linear [63]. It was also determined that the increasing dependent factors such as sorbent dosage saw an increase in adsorption effectiveness for both anti-inflammatory drugs that were tested [63]. The rate of adsorption depended on the $\mathrm{pH}$ of the solution for maximum removal, which was determined to be around a $\mathrm{pH}$ of 2-6 [63]. 


\section{Agricultural Applications of Chitin}

Chitin can be practically applied to the medical and environmental sectors, so it comes as no surprise that this biopolymer contains different properties enabling it to act as a novel solution to many issues present in the agricultural sector. The nature of synthetic chemicals and their effect on the environment is a cause for concern when maintaining farms. This has led many government agencies to place strict regulations that somewhat limit the use of pesticides, fertilizers, and plant growth regulators due to the potentially harmful effects these chemicals have, causing an increased need for a suitable organic replacement $[64,65]$. Chitin can play a key role in the agricultural industry due to its water-soluble nature [64,65]. The different applications of chitin in the agricultural industry have been well documented with even more novel processes still in development $[64,65]$. Some of those would include, but are not limited to, being used as fertilizers, soil conditioning agents, plant disease control agents, antitranspirants, fruit retardants, and seed coatings [64,65]. Furthermore, chitin can increase the natural defense mechanisms in plants by upregulating plant growth regulators, growth stimulants, anti-stress agents, and elicitors for the production of secondary metabolites $[64,65]$.

\subsection{Pathogen Resistance}

Chitin plays an integral part in fungal pathogenicity. Even though plants do not produce chitin directly, they do secrete enzymes that are involved in the breakdown of chitin [66-68]. This characteristic is important, as the host plant relies on the number of chitinases secreted from plant cells to resist pathogens [66-68]. Consequently, chitin fragments are released from the fungal cell wall, which induces plant defense mechanisms that help with protecting the host plant from fungal pathogens [66-68]. Following this, researchers understood that increasing the expression of chitinase in plants would impart noticeable resistance to fungal pathogens [66-68]. The genes that control the expression of a plant's innate defense mechanism have been previously studied and have shown that chitooligosaccharides are important in the controlled expression of plant genes [66-68]. Overall, plant disease resistance arises from chitin's unique ability to control the signal transduction pathway to promptly fend off pathogens [66-68].

The class of chitinases known simply as class I chitinases reside in high levels in vacuoles when the host plant is wounded or infected by a pathogen $[68,69]$. When wanting to create a transgenic plant using genes from other plants and placing those same genes into different plant species, chitinase has increased pathogen resistance in various plant species $[68,69]$. Species including tobacco, tomatoes, carrots, cucumbers, pickled cucumbers, rice, grapes, apples, potatoes, and broccoli were all transformed by chitinases from Trichoderma harzianum, a parasitic fungus that resulted in the plants showing resistance to various other pathogens $[68,69]$. After implementing the transgenic chitinase model into other plants, more studies were developed to truly test the limits of the degradation enzyme as a plant defense mechanism. The effects of over-expression of class I chitinase genes to enhance resistance in cacao, a raw ingredient for chocolate, against the pathogen Colletotrichum gloeosporides were studied $[68,69]$. The study over-expressed the gene TcChil that was obtained from Agrobacterium and performed an in vivo bioassay with the detached left of Theobroma cacao L. that was infected by Colletotrichum gloeosporioides [68,69]. The level of chitinase was measured using in vitro fluorometric assay, which determined that the transgene in the transgenic lines were expressed almost six times more than the nontransgenic lines' and the control plant's levels of chitinase [68,69]. Visual evaluation was determined by performing a leaf disk bioassay, which illustrated that the TcChil transgenic leaves limited the growth of fungus significantly when compared to the leaves of the control plant, which saw more leaf necrosis [68,69].

Plant defense mechanisms are not only localized to chitinases activity, but also have a wide variety of different immune responses that are set in place to slow down and halt pathogen proliferation $[70,71]$. Such responses are initiated through conserved ligands that activate specific receptors, triggering cascading responses that slow down or diminish the 
pathogens' ability to spread within the host [70,71]. Pathogens that do bypass this response can deliver their effector proteins into the host cell's cytoplasm, essentially taking over the host benefitting the pathogen [70,71]. Effector proteins that inhibit pattern-triggered immunity cause plants to use alternative mechanisms, such as intracellular immune receptors set in place to identify effector proteins by triggering cell death as an appropriate response [70,71]. The best-known cell-surface localized receptor is CERK1, a chitin receptor, which recognizes bacterial infections and triggers immunity in plants [70,71]. To test the importance of the receptor, a recent study looking at the effects of receptor-like kinases in other species of plants to determine if they have the same properties as CERK1-like receptors that control plant immunity [72]. The study looked at legume plant peas, Pisum sativum, and questioned how certain genes control plant immunity [72]. It was determined that PsLyk9 was upregulated when Pisum sativum detected a pathogenic fungi infection and that the gene could be a possible candidate for a CERK1-like receptor found in the pea genome [72]. An increase in the rate of infection was reported as resulting from fungal pathogens in those plants that had their genes knocked out and downregulated [72]. Furthermore, levels of defense-response genes were lower in Pisum sativum root when $P_{s} L y k 9$ was downregulated [72]. The results further showed that $P_{s} L y k 9$ 's ability to detect short chitooligosaccharides, the key signals for beneficial microorganisms, was greatly reduced [72]. Finally, the researchers in this study concluded that the gene PsLyk9 is most likely a CERK1 like a receptor and the downregulation of the gene confers with the pea plant's ability to protect itself from harmful pathogens [72].

\subsection{Crop Growth}

The interest surrounding the different applications of chitin and its derivatives has allowed researchers to further investigate the polysaccharide's involvement in different agricultural practices. The use of chemical fertilizers for plant growth has been the gold standard for many farms around the world, but these agrochemicals have resulted in countless problems, including decreased soil fertility, biodiversity loss, environmental damage, and water and food pollution, which have been linked to serious human health concerns $[73,74]$. Due to the environmentally damaging nature of chemical fertilizers, many have started to switch to more eco-friendly fertilizers in crop production [73,74]. Furthermore, research is currently being performed at an accelerated rate to develop natural plant growth regulators for exceptionally sustainable agriculture for future practices $[73,74]$. Water-soluble oligosaccharide fragments obtained by grinding chitin and its derivatives have been hypothesized as a substitute, being considered by the scientific community as the best natural plant growth stimulant that is non-invasive [73,74]. These water-soluble oligosaccharide fragments are viewed to have a profound effect on fruit weight, fruit yield, plant height, leaf numbers, overall increased biomass, canopy diameter, spike number, increased seed germination, and growth in flower species [74,75]. These effects can be attributed to the short-chain oligomers of chitin, roughly 6-7 oligomers in length, producing lower reactive oxygen species in plants than larger chitin oligomers [76]. Moreover, short-chain oligomers of chitin that bind to lipids (lippchitooligosaccharides, LCOs) and nodulation factors originating from symbiotic bacteria and fungi have been shown to increase plant growth early in development [76].

The practical applications of chitin on crop growth come in various forms for improving soil quality and plant growth $[77,78]$. Simply put, treating the soil with chitin has been known to lower the rate of infection of nematodes on plant roots and to further increase suppressiveness against many soil-borne fungal pathogens [77,78]. Furthermore, the suppressive nature of chitin added to the soil often causes changes to beneficial microbiota in the soil and rhizosphere that directly favor plant development $[77,78]$. Many studies have concluded that rhizosphere organisms not only have a beneficial effect on plant growth, but also have a positive impact on nitrogen-fixing bacteria and mycorrhizal fungi $[77,78]$. In addition, chitin can increase the positive effect that rhizosphere organisms have on plants by further proliferating growth $[77,78]$. In this context, a study looked into the effects that 
chitin has on potting soil used to grow lettuce and the authors measured the growth rate and the ability to carry on their leaves two zoonotic bacterial pathogens, Escherichia coli and Salmonella enterica $[77,78]$. The researchers in this study wanted to test the growth of two bacteria on the lettuce leaves to understand how chitin would influence the growth of the bacterium and apply that on a larger commercial scale, which is linked to outbreaks commonly associated with the consumption of lettuce $[77,78]$. The results concluded that biomass significantly increased and the growth of Salmonella enterica on lettuce greatly decreased. However, Escherichia coli survival was lower, although the results were not significant $[77,78]$. Moreover, results showed that the concentrations of chitin added to the soil produced a dramatic increase of other bacterial and fungal genera, which control plant growth, the nitrogen cycle, and chitin degradation $[77,78]$.

\subsection{Crop Defense}

Pest management, through various insecticides, such as organophosphates, carbamates, and pyrethroids, has an important role in protecting crops by decreasing the rate of disease transmission $[79,80]$. However, the use of these chemicals can present major environmental and health risks. Therefore, there is an increased desire to develop ecofriendly insecticides through different non-invasive building materials like chitin [79,80], and recently developed analytical methods could be applied for its identification [81]. Aforementioned, chitin can be found in the cuticles of insects. However, even though plants cannot produce chitin directly, the biopolymer can be used for various signaling pathways to create an alternative insect-specific insecticide [79]. With this knowledge, the development of chitin synthesis inhibitors (CSI) impedes the biosynthesis of chitin in insects, acting as an effective integrated pest management system [79].

Benzoylphenyl ureas, a common CSI, represent an inhibitor that interferes with chitin deposition [79]. Their effect on chitin varies as there are more than 10,000 different types of benzoylphenyl ureas and 15 benzoylphenyl ureas currently out on the market, but the overall effect is the same for dealing with sanitary insect pests [79]. The benzoylphenyl urea insecticide diflubenzuron, otherwise known as DFB or Dimilin, is a CSI that inhibits a key development process in insects known as molting $[82,83]$. The pervasive characteristic of molting is important to the life cycle of insects as it allows them to grow [84]. More precisely, molting is triggered by different circumstances, like a change in size that marks the transition between the end of the larval growing phase and the formation of the adult exoskeleton [84]. The compound diflubenzuron seemingly prevents the formation of the cuticle, which is largely made up of chitin, affecting the procuticle layers and causing abortive molting $[82,83]$. To understand the wider range of effects of diflubenzuron, a study was performed on a known pest Tribolium castaneum, otherwise known as the red flour beetle $[82,83]$. The study fed both larvae and adult beetle wheat that had different concentrations of diflubenzuron. The observable result showed abortive molting, hatching defects, and lower levels of chitin in the larval cuticle, eggs, and peritrophic matrix. Further examination using an electron microscope reported that the larval cuticle presented major cellular damage and loss of the lamellate layer of the procuticle $[82,83]$.

\section{Concluding Remarks}

Ultimately, chitin has many practical applications within the medical, environmental, and agricultural sectors. This biopolymer is an important element for numerous genera and can be harvested without putting a species at risk of endangerment. The use of chitin in cancer diagnosis and treatments, tissue engineering, wound dressing, and drug delivery has pushed the boundaries and paved the way for future developments in the medical field. Within an environmental context, this polymer has shown impactful results in the remediation process of inorganic and organic contaminants that hurt surrounding conditions. Finally, chitin has also shown promise within agricultural systems as a suitable substitute in protecting plants against pathogens and promoting plant growth. Thus, specific research groups and environmental agencies have demonstrated interest in further 
integrating this naturally occurring polysaccharide into other areas of our lives in need of improvement.

Author Contributions: Conceptualization, M.A.R.; resources, M.A.R. and U.D.; writing-original draft preparation, M.A.R., U.D., E.S. and P.B.; writing-review and editing, M.A.R. and E.S.; visualization, M.A.R., U.D. and L.P.; graphics, L.P. and M.A.R.; supervision, M.A.R.; project administration, M.A.R.; funding acquisition, M.A.R. All authors have read and agreed to the published version of the manuscript.

Funding: This research was funded by the Innovation Assistant Program of IRAP-NRC (Project Nos.: 950567, 959949, 967148), Canada.

Institutional Review Board Statement: Not applicable.

Informed Consent Statement: Not applicable.

Data Availability Statement: Not applicable.

Acknowledgments: The research team at CCCR and A.R.E.S acknowledge the lead supervisor Azizur Rahman for his contributions to the field.

Conflicts of Interest: The authors declare no conflict of interest.

\section{References}

1. Rahman, M.A.; Halfar, J. First evidence of chitin in calcified coralline algae: New insights into the calcification process of Clathromorphum compactum. Sci. Rep. 2014, 4, 6162. [CrossRef]

2. Jang, M.-K.; Kong, B.-G.; Jeong, Y.-I.; Lee, C.H.; Nah, J.-W. Physicochemical characterization of $\alpha$-chitin, $\beta$-chitin, and $\gamma$-chitin separated from natural resources. J. Polym. Sci. Part A Polym. Chem. 2004, 42, 3423-3432. [CrossRef]

3. Hajji, S.; Younes, I.; Ghorbel-Bellaaj, O.; Hajji, R.; Rinaudo, M.; Nasri, M.; Jellouli, K. Structural differences between chitin and chitosan extracted from three different marine sources. Int. J. Biol. Macromol. 2014, 65, 298-306. [CrossRef]

4. Moussian, B.; Schwarz, H.; Bartoszewski, S.; Nüsslein-Volhard, C. Involvement of chitin in exoskeleton morphogenesis in Drosophila melanogaster. J. Morphol. 2005, 264, 117-130. [CrossRef]

5. Rahman, M.A.; Halfar, J.; Adey, W.H.; Nash, M.; Paulo, C.; Dittrich, M. The role of chitin-rich skeletal organic matrix on the crystallization of calcium carbonate in the crustose coralline alga Leptophytum foecundum. Sci. Rep. 2019, 9, 1-8. [CrossRef] [PubMed]

6. Boßelmann, F.; Romano, P.; Fabritius, H.; Raabe, D.; Epple, M. The composition of the exoskeleton of two crustacea: The American lobster Homarus americanus and the edible crab Cancer pagurus. Thermochim. Acta 2007, 463, 65-68. [CrossRef]

7. Merzendorfer, H.; Zimoch, L. Chitin metabolism in insects: Structure, function and regulation of chitin synthases and chitinases. J. Exp. Biol. 2003, 206, 4393-4412. [CrossRef] [PubMed]

8. Zhu, K.Y.; Merzendorfer, H.; Zhang, W.; Zhang, J.; Muthukrishnan, S. Biosynthesis, Turnover, and Functions of Chitin in Insects. Annu. Rev. Èntomol. 2016, 61, 177-196. [CrossRef]

9. Rocha, J.; García-Carreño, F.; Muhlia-Almazán, A.; Peregrino-Uriarte, A.B.; Yépiz-Plascencia, G.; Cordova-Murueta, J.H. Cuticular chitin synthase and chitinase mRNA of whiteleg shrimp Litopenaeus vannamei during the molting cycle. Aquaculture 2012, 330-333, 111-115. [CrossRef]

10. Nagasawa, H. The crustacean cuticle: Structure, composition and mineralization. Front. Biosci. 2012, 4, 711-720. [CrossRef]

11. Cohen, E. Chitin synthesis and inhibition: A revisit. Pest Manag. Sci. 2001, 57, 946-950. [CrossRef]

12. Merzendorfer, H. The cellular basis of chitin synthesis in fungi and insects: Common principles and differences. Eur. J. Cell Biol. 2011, 90, 759-769. [CrossRef] [PubMed]

13. Dermauw, W.; Van Leeuwen, T. The ABC gene family in arthropods: Comparative genomics and role in insecticide transport and resistance. Insect Biochem. Mol. Biol. 2014, 45, 89-110. [CrossRef]

14. Glazer, L.; Tom, M.; Weil, S.; Roth, Z.; Khalaila, I.; Mittelman, B.; Sagi, A. Hemocyanin with phenoloxidase activity in the chitin matrix of the crayfish gastrolith. J. Exp. Biol. 2013, 216, 1898-1904. [CrossRef] [PubMed]

15. Glazer, L.; Shechter, A.; Tom, M.; Yudkovski, Y.; Weil, S.; Aflalo, E.; Pamuru, R.R.; Khalaila, I.; Bentov, S.; Berman, A.; et al. A Protein Involved in the Assembly of an Extracellular Calcium Storage Matrix. J. Biol. Chem. 2010, 285, 12831-12839. [CrossRef]

16. Pachapur, V.L.; Guemiza, K.; Rouissi, T.; Sarma, S.J.; Brar, S.K. Novel biological and chemical methods of chitin extraction from crustacean waste using saline water. J. Chem. Technol. Biotechnol. 2016, 91, 2331-2339. [CrossRef]

17. Borić, M.; Vicente, F.A.; Jurković, D.L.; Novak, U.; Likozar, B. Chitin isolation from crustacean waste using a hybrid demineralization/DBD plasma process. Carbohydr. Polym. 2020, 246, 116648. [CrossRef]

18. Olsen, R.L.; Toppe, J.; Karunasagar, I. Challenges and realistic opportunities in the use of by-products from processing of fish and shellfish. Trends Food Sci. Technol. 2014, 36, 144-151. [CrossRef] 
19. Pal, J.; Verma, H.O.; Munka, V.K.; Maurya, S.K.; Roy, D.; Kumar, J. Biological method of chitin extraction from shrimp waste an eco-friendly low cost technology and its advanced application. Int. J. Fish. Aquat. Stud. IJFAS 2014, 1, 104-107. Available online: www.fisheriesjournal.com (accessed on 12 May 2021).

20. Hours, R.A.; Gortari, M.C. Biotechnological processes for chitin recovery out of crustacean waste: A mini-review. Electron. J. Biotechnol. 2013, 16, 14. [CrossRef]

21. Liu, S.; Sun, J.; Yu, L.; Zhang, C.; Bi, J.; Zhu, F.; Qu, M.; Jiang, C.; Yang, Q. Extraction and Characterization of Chitin from the Beetle Holotrichia parallela Motschulsky. Mol. 2012, 17, 4604-4611. [CrossRef] [PubMed]

22. Zhang, M.; Haga, A.; Sekiguchi, H.; Hirano, S. Structure of insect chitin isolated from beetle larva cuticle and silkworm (Bombyx mori) pupa exuvia. Int. J. Biol. Macromol. 2000, 27, 99-105. [CrossRef]

23. Yang, T.-L. Chitin-based Materials in Tissue Engineering: Applications in Soft Tissue and Epithelial Organ. Int. J. Mol. Sci. 2011, 12, 1936-1963. [CrossRef]

24. Wan, A.C.; Tai, B.C. CHITIN-A promising biomaterial for tissue engineering and stem cell technologies. Biotechnol. Adv. 2013, 31, 1776-1785. [CrossRef]

25. Madhumathi, K.; Kumar, P.S.; Kavya, K.; Furuike, T.; Tamura, H.; Nair, S.; Jayakumar, R. Novel chitin/nanosilica composite scaffolds for bone tissue engineering applications. Int. J. Biol. Macromol. 2009, 45, 289-292. [CrossRef]

26. Wojtowicz, A.M.; Oliveira, S.; Carlson, M.W.; Zawadzka, A.; Rousseau, C.F.; Baksh, D. The importance of both fibroblasts and keratinocytes in a bilayered living cellular construct used in wound healing. Wound Repair Regen. Off. Publ. Wound Heal. Soc. Eu-Ropean Tissue Repair Soc. 2014, 22, 246-255. [CrossRef]

27. Souren, J.E.M.; Ponec, M.; van Wijk, R. Contraction of collagen by human fibroblasts and keratinocytes. Vitr. Cell. Dev. Biol.-Anim. 1989, 25, 1039-1045. [CrossRef] [PubMed]

28. Nettles, D.L.; Elder, S.H.; Gilbert, J.A. Potential Use of Chitosan as a Cell Scaffold Material for Cartilage Tissue Engineering. Tissue Eng. 2002, 8, 1009-1016. [CrossRef] [PubMed]

29. Kuo, Y.-C.; Ku, I.-N. Cartilage Regeneration by Novel Polyethylene Oxide/Chitin/Chitosan Scaffolds. Biomacromolecules 2008, 9 , 2662-2669. [CrossRef]

30. Freier, T.; Montenegro, R.; Koh, H.S.; Shoichet, M.S. Chitin-based tubes for tissue engineering in the nervous system. Biomaterials 2005, 26, 4624-4632. [CrossRef]

31. Islam, S.; Bhuiyan, M.A.R.; Islam, M.N. Chitin and Chitosan: Structure, Properties and Applications in Biomedical Engineering. J. Polym. Environ. 2017, 25, 854-866. [CrossRef]

32. Ahmed, S.; Ikram, S. Chitosan Based Scaffolds and Their Applications in Wound Healing. Achiev. Life Sci. 2016, 10, 27-37. [CrossRef]

33. Jiménez-Gómez, C.P.; Cecilia, J.A. Chitosan: A Natural Biopolymer with a Wide and Varied Range of Applications. Molecules 2020, 25, 3981. [CrossRef]

34. Kumar, P.S.; Abhilash, S.; Manzoor, K.; Nair, S.; Tamura, H.; Jayakumar, R. Preparation and characterization of novel $\beta-$ chitin/nanosilver composite scaffolds for wound dressing applications. Carbohydr. Polym. 2010, 80, 761-767. [CrossRef]

35. Jayakumar, R.; Menon, D.; Manzoor, K.; Nair, S.; Tamura, H. Biomedical applications of chitin and chitosan based nanomaterialsA short review. Carbohydr. Polym. 2010, 82, 227-232. [CrossRef]

36. Yusof, N.L.B.M.; Wee, A.; Lim, L.Y.; Khor, E. Flexible chitin films as potential wound-dressing materials: Wound model studies. J. Biomed. Mater. Res.-Part A 2003, 66, 224-232. [CrossRef]

37. Hu, S.; Bi, S.; Yan, D.; Zhou, Z.; Sun, G.; Cheng, X.; Chen, X. Preparation of composite hydroxybutyl chitosan sponge and its role in promoting wound healing. Carbohydr. Polym. 2018, 184, 154-163. [CrossRef]

38. Ehterami, A.; Salehi, M.; Farzamfar, S.; Samadian, H.; Vaez, A.; Ghorbani, S.; Ai, J.; Sahrapeyma, H. Chitosan/alginate hydrogels containing Alpha-tocopherol for wound healing in rat model. J. Drug Deliv. Sci. Technol. 2019, 51, 204-213. [CrossRef]

39. Lee, K.Y.; Mooney, D.J. Alginate: Properties and biomedical applications. Prog. Polym. Sci. 2012, 37, 106-126. [CrossRef] [PubMed]

40. Rejinold, N.S.; Chennazhi, K.P.; Tamura, H.; Nair, S.V.; Rangasamy, J. Multifunctional Chitin Nanogels for Simultaneous Drug Delivery, Bioimaging, and Biosensing. ACS Appl. Mater. Interfaces 2011, 3, 3654-3665. [CrossRef] [PubMed]

41. Parhi, R. Drug delivery applications of chitin and chitosan: A review. Environ. Chem. Lett. 2020, 18, 577-594. [CrossRef]

42. Jayakumar, R.; Prabaharan, M.; Nair, S.; Tokura, S.; Tamura, H.; Selvamurugan, N. Novel carboxymethyl derivatives of chitin and chitosan materials and their biomedical applications. Prog. Mater. Sci. 2010, 55, 675-709. [CrossRef]

43. Narayanan, D.; Jayakumar, R.; Chennazhi, K.P. Versatile carboxymethyl chitin and chitosan nanomaterials: A review. Wiley Interdiscip. Rev. Nanomed. Nanobiotechnol. 2014, 6, 574-598. [CrossRef]

44. Dev, A.; Binulal, N.; Anitha, A.; Nair, S.; Furuike, T.; Tamura, H.; Jayakumar, R. Preparation of poly(lactic acid)/chitosan nanoparticles for anti-HIV drug delivery applications. Carbohydr. Polym. 2010, 80, 833-838. [CrossRef]

45. Mi, F.-L.; Shyu, S.-S.; Lin, Y.-M.; Wu, Y.-B.; Peng, C.-K.; Tsai, Y.-H. Chitin/PLGA blend microspheres as a biodegradable drug delivery system: A new delivery system for protein. Biomaterials 2003, 24, 5023-5036. [CrossRef]

46. Peng, C.-W.; Li, Y. Application of Quantum Dots-Based Biotechnology in Cancer Diagnosis: Current Status and Future Perspectives. J. Nanomater. 2010, 2010, 1-11. [CrossRef]

47. Karagozlu, M.Z.; Kim, S.-K. Chapter Twelve-Anticancer Effects of Chitin and Chitosan Derivatives. In Advances in Food and Nutrition Research; Kim, S.-K., Ed.; Academic Press: Waltham, MA, USA, 2014; Volume 72, pp. 215-225. 
48. Peter, S.; Lyczko, N.; Gopakumar, D.; Maria, H.J.; Nzihou, A.; Thomas, S. Chitin and Chitosan Based Composites for Energy and Environmental Applications: A Review. Waste Biomass-Valorization 2021, 12, 4777-4804. [CrossRef]

49. Rameshthangam, P.; Solairaj, D.; Arunachalam, G.; Ramasamy, P.; Veterinary, T.N.; Nadu, T.J. Chitin and Chitinases: Biomedical and Environmental Applications of Chitin and its Derivatives. J. Enzymes 2018, 1, 20-43. [CrossRef]

50. Xu, R.; Mao, J.; Peng, N.; Luo, X.; Chang, C. Chitin/clay microspheres with hierarchical architecture for highly efficient removal of organic dyes. Carbohydr. Polym. 2018, 188, 143-150. [CrossRef] [PubMed]

51. Cao, Y.-L.; Pan, Z.-H.; Shi, Q.-X.; Yu, J.-Y. Modification of chitin with high adsorption capacity for methylene blue removal. Int. J. Biol. Macromol. 2018, 114, 392-399. [CrossRef]

52. Schirmer, R.H.; Adler, H.; Pickhardt, M.; Mandelkow, E. Lest we forget you-Methylene blue. Neurobiol. Aging 2011, 32, 2325.e7-2325.e16. [CrossRef]

53. Druzian, S.P.; Zanatta, N.P.; Côrtes, L.N.; Streit, A.F.M.; Dotto, G.L. Preparation of chitin nanowhiskers and its application for crystal violet dye removal from wastewaters. Environ. Sci. Pollut. Res. 2019, 26, 28548-28557. [CrossRef] [PubMed]

54. Meshkat, S.S.; Nezhad, M.N.; Bazmi, M.R. Investigation of Carmine Dye Removal by Green Chitin Nanowhiskers Adsorbent. Emerg. Sci. J. 2019, 3, 187-194. [CrossRef]

55. González, J.A.; Villanueva, M.E.; Piehl, L.L.; Copello, G. Development of a chitin/graphene oxide hybrid composite for the removal of pollutant dyes: Adsorption and desorption study. Chem. Eng. J. 2015, 280, 41-48. [CrossRef]

56. Ma, Z.; Liu, D.; Zhu, Y.; Li, Z.; Li, Z.; Tian, H.; Liu, H. Graphene oxide/chitin nanofibril composite foams as column adsorbents for aqueous pollutants. Carbohydr. Polym. 2016, 144, 230-237. [CrossRef]

57. Nasrollahzadeh, M.; Sajjadi, M.; Iravani, S.; Varma, R.S. Starch, cellulose, pectin, gum, alginate, chitin and chitosan derived (nano)materials for sustainable water treatment: A review. Carbohydr. Polym. 2021, 251, 116986. [CrossRef]

58. Boulaiche, W.; Hamdi, B.; Trari, M. Removal of heavy metals by chitin: Equilibrium, kinetic and thermodynamic studies. Appl. Water Sci. 2019, 9, 39. [CrossRef]

59. Saravanan, D.; Gomathi, T.; Sudha, P. Sorption studies on heavy metal removal using chitin/bentonite biocomposite. Int. J. Biol. Macromol. 2013, 53, 67-71. [CrossRef]

60. Nithya, R.; Sudha, P.N. Removal of heavy metals from tannery effluent using chitosan-g-poly(butyl acrylate)/bentonite nanocomposite as an adsorbent. Text. Cloth. Sustain. 2017, 2, 1. [CrossRef]

61. Saxena, R.; Saxena, M.; Lochab, A. Recent Progress in Nanomaterials for Adsorptive Removal of Organic Contaminants from Wastewater. ChemistrySelect 2020, 5, 335-353. [CrossRef]

62. Żółtowska-Aksamitowska, S.; Bartczak, P.; Zembrzuska, J.; Jesionowski, T. Removal of hazardous non-steroidal anti-inflammatory drugs from aqueous solutions by biosorbent based on chitin and lignin. Sci. Total. Environ. 2018, 612, 1223-1233. [CrossRef] [PubMed]

63. Gwenzi, W.; Chaukura, N. Organic contaminants in African aquatic systems: Current knowledge, health risks, and future research directions. Sci. Total. Environ. 2018, 619-620, 1493-1514. [CrossRef] [PubMed]

64. Shamshina, J.L.; Kelly, A.; Oldham, T.; Rogers, R.D. Agricultural uses of chitin polymers. Environ. Chem. Lett. 2020, 18, 53-60. [CrossRef]

65. Ramírez, M.Á.; Rodríguez, A.T.; Alfonso, L.; Peniche, C.; Experimental, E.; Nacional, I.; Agrícolas, D.C. Chitin is a biodegradable polymer widely spread in nature. Biotecnol. Apl. 2010, 27, 270-276.

66. Wan, J.; Zhang, X.-C.; Stacey, G. Chitin signaling and plant disease resistance. Plant Signal. Behav. 2008, 3, 831-833. [CrossRef] [PubMed]

67. Eckardt, N.A. Chitin Signaling in Plants: Insights into the Perception of Fungal Pathogens and Rhizobacterial Symbionts. Plant Cell 2008, 20, 241-243. [CrossRef] [PubMed]

68. Maximova, S.N.; Marelli, J.-P.; Young, A.; Pishak, S.; Verica, J.A.; Guiltinan, M.J. Over-expression of a cacao class I chitinase gene in Theobroma cacao L. enhances resistance against the pathogen, Colletotrichum gloeosporioides. Planta 2006, 224, 740-749. [CrossRef]

69. Iqbal, M.M.; Nazir, F.; Ali, S.; Asif, M.A.; Zafar, Y.; Iqbal, J.; Ali, G.M. Over Expression of Rice chitinase Gene in Transgenic Peanut (Arachis hypogaea L.) Improves Resistance Against Leaf Spot. Mol. Biotechnol. 2012, 50, 129-136. [CrossRef]

70. Yamaguchi, K.; Yamada, K.; Ishikawa, K.; Yoshimura, S.; Hayashi, N.; Uchihashi, K.; Ishihama, N.; Kishi-Kaboshi, M.; Takahashi, A.; Tsuge, S.; et al. A Receptor-like Cytoplasmic Kinase Targeted by a Plant Pathogen Effector Is Directly Phosphorylated by the Chitin Receptor and Mediates Rice Immunity. Cell Host Microbe 2013, 13, 347-357. [CrossRef]

71. Petutschnig, E.K.; Jones, A.M.; Serazetdinova, L.; Lipka, U.; Lipka, V. The Lysin Motif Receptor-like Kinase (LysM-RLK) CERK1 Is a Major Chitin-binding Protein in Arabidopsis thaliana and Subject to Chitin-induced Phosphorylation. J. Biol. Chem. 2010, 285, 28902-28911. [CrossRef]

72. Leppyanen, I.V.; Shakhnazarova, V.Y.; Shtark, O.Y.; Vishnevskaya, N.A.; Tikhonovich, I.A.; Dolgikh, E.A. Receptor-Like Kinase LYK9 in Pisum sativum L. Is the CERK1-Like Receptor that Controls Both Plant Immunity and AM Symbiosis Development. Int. J. Mol. Sci. 2018, 19, 8. [CrossRef]

73. Li, K.; Xing, R.; Liu, S.; Li, P. Chitin and Chitosan Fragments Responsible for Plant Elicitor and Growth Stimulator. J. Agric. Food Chem. 2020, 68, 12203-12211. [CrossRef] [PubMed]

74. Malerba, M.; Cerana, R. Recent Applications of Chitin- and Chitosan-Based Polymers in Plants. Polymers 2019, 11, 839. [CrossRef]

75. Malerba, M.; Cerana, R. Chitosan Effects on Plant Systems. Int. J. Mol. Sci. 2016, 17, 996. [CrossRef] 
76. Winkler, A.J.; Nuñez, J.A.D.; Aranaz, I.; Poza-Carrión, C.; Ramonell, K.; Somerville, S.; Berrocal-Lobo, M. Short-Chain Chitin Oligomers: Promoters of Plant Growth. Mar. Drugs 2017, 15, 40. [CrossRef]

77. Debode, J.; De Tender, C.; Soltaninejad, S.; Van Malderghem, C.; Haegeman, A.; Van Der Linden, I.; Cottyn, B.; Heyndrickx, M.; Maes, M. Chitin Mixed in Potting Soil Alters Lettuce Growth, the Survival of Zoonotic Bacteria on the Leaves and Associated Rhizosphere Microbiology. Front. Microbiol. 2016, 7, 565. [CrossRef] [PubMed]

78. Hallmann, J.; Rodríguez-Kábana, R.; Kloepper, J. Chitin-mediated changes in bacterial communities of the soil, rhizosphere and within roots of cotton in relation to nematode control. Soil Biol. Biochem. 1999, 31, 551-560. [CrossRef]

79. Sun, R.; Liu, C.; Zhang, H.; Wang, Q. Benzoylurea Chitin Synthesis Inhibitors. J. Agric. Food Chem. 2015, 63, 6847-6865. [CrossRef] [PubMed]

80. Lewis, W.J.; van Lenteren, J.C.; Phatak, S.C.; Tumlinson, J.H. A total system approach to sustainable pest management. Proc. Natl. Acad. Sci. USA 1997, 94, 12243-12248. [CrossRef] [PubMed]

81. Tsurkan, M.V.; Voronkina, A.; Khrunyk, Y.; Wysokowski, M.; Petrenko, I.; Ehrlich, H. Progress in chitin analytics. Carbohydr. Polym. 2021, 252, 117204. [CrossRef] [PubMed]

82. Merzendorfer, H.; Kim, H.S.; Chaudhari, S.S.; Kumari, M.; Specht, C.A.; Butcher, S.; Brown, S.J.; Manak, J.R.; Beeman, R.W.; Kramer, K.J.; et al. Genomic and proteomic studies on the effects of the insect growth regulator diflubenzuron in the model beetle species Tribolium castaneum. Insect Biochem. Mol. Biol. 2012, 42, 264-276. [CrossRef] [PubMed]

83. Van Eck, W. Mode of action of two benzoylphenyl ureas as inhibitors of chitin synthesis in insects. Insect Biochem. 1979, 9, 295-300. [CrossRef]

84. Nijhout, H.F. Physiological Control of Molting in Insects. Am. Zoöl. 1981, 21, 631-640. [CrossRef] 